\title{
FORMULATION AND EVALUATION OF SUSTAINED RELEASE MATRIX TABLETS OF ANTI-ASTHMATIC AGENT USING VARIOUS POLYMERS
}

\author{
Prakash B. Mote*, Pavan K. Rawat, Shailendra K Singh, Nityanand S. Zadbuke, Amarjit A. Salunke, Vivek B. Rajendra
}

Shreya Life Sciences Pvt. Ltd. Aurangabad-431136

*Corresponding author's Email: prakashmote@gmail.com

\begin{abstract}
:
The objective of the present study was to develop Salbutamol sulphate matrix tablets, sustained release dosage form, for the treatment of Chronic Obstructive Pulmonary Disease (COPD). Compatibility study was performed through Fourier Transformer Infrared spectroscopy revealed that there no interaction between drug and polymers. Matrix tablets were prepared by wet granulation method using different concentration of Hydroxypropylmethylcellulose K100M (HPMC K100M), HPMC K15M and Ethyl Cellulose (EC). Prepared formulations were subjected to Pre-compression parameters like angle of repose, bulk and tapped density, Hausner's ratio and car's index and post-compression parameters like hardness, friability, thickness, \% drug content, weight variation, swelling index. All the formulations resulted in acceptable limits. Tablets were subjected to In-Vitro drug release in $0.1 \mathrm{~N} \mathrm{HCl}(\mathrm{pH} 1.2)$ for first 2 hours followed by phosphate buffer ( $\mathrm{pH} \mathrm{6.8)} \mathrm{for} \mathrm{remaining} 10$ hours. In-vitro drug release data were fitting to zero order and Higuchi equation indicated that diffusion along with erosion could be the mechanism of drug release. It was observed that formulation F2 containing HPMC K100M exhibited the best release profile and able to sustain the drug release for prolong period of time. Swelling study suggested that when the matrix tablets come in contact with the dissolution medium, they take up water and swells, forming a gel layer around the matrix and simultaneously erosion also takes place.

Keywords: Salbutamol sulphate, matrix tablet, Hydroxypropylmethylcellulose K100M, Hydroxypropylmethylcellulose K15M and Ethyl Cellulose.
\end{abstract}

\section{INTRODUCTION:}

Sustained release drug delivery systems are designed to achieve a prolonged therapeutic effect by continuously releasing medication over an extended period of time. The goal in designing oral sustained or controlled delivery systems is to reduce the frequency of the dosing or to increase effectiveness of the drug by localizing at the site of action, reducing the dose required or provide uniform drug delivery, thereby also improving patient compliance. Sustained release dosage forms provide a better control of plasma drug levels, less dosage frequency, less side effect, increased efficacy and constant delivery. 1,2

Asthma is an extremely common disorder which affects many people. Asthma is viewed as an inflammatory condition with bronchial hyperactivity and bronchospasm. Continuous therapy is required for the treatment of asthma. Salbutamol sulphate is the drug of choice as a bronchodilator in the management of reversible airways obstruction in case of asthma and in some patients with chronic obstructive pulmonary disorders. ${ }^{3}$

Salbutamol sulphate is a short acting highly selective $\beta-2$ adrenoceptor agonist with bronchodilating property is widely used for the management of chronic obstructive pulmonary disease (COPD) which includes bronchial asthma, chronic bronchitis and emphysema. Salbutamol sulphate is almost completely absorbed from the gastrointestinal tract after oral administration. The reported plasma half-life of Salbutamol sulphate is $2.85 \pm 0.85$ and the peak plasma concentration occurs at about 30 minutes after an oral dose. The protein binding affinity of Salbutamol sulphate is $7 \pm 1 \%$ and undergoes considerable first pass metabolism. The drug as sulphate is soluble in 1 to 4 molar parts of water, due to the hydrophilic nature it is (c) 2011, JDDT. All Rights Reserved readily excreted through urine. ${ }^{4}$ Sustained release matrix tablets are relatively easy to fabricate by incorporating drug particles in slowly disintegrating or inert porous materials. Drug release occurs either by diffusion through the matrix or by erosion of the matrix or by a combination of both diffusion and erosion. ${ }^{4}$ Oral sustained release dosage forms have been used to improve therapeutic efficacy and achieve a good patient compliance. ${ }^{5}$

\section{MATERIALS AND METHOD}

Salbutamol Sulphate obtained as gift sample from Shreya Life Sciences Pvt. Ltd. Aurangabad, HPMC K100M, HPMC K15M, Ethyl Cellulose, Lactose Monohydrate, Isopropyl Alcohol, Magnisium Stearate and Talc were of analytical grade.

\section{Experimental Work}

Sustained release matrix tablets of Salbutamol sulphate were prepared by wet granulation method according to the formula given in table. All the ingredients were passed through 40 mesh sieve separately. The drug and diluents was mixed by small portion of both each time and blending it to get a uniform mixture kept aside. Then add the isopropyl alcohol as binder then granules kept for drying for $1 \mathrm{hrs}$ at $55^{\circ} \mathrm{C}$ then dried granules are lubricated with magnesium stearate and talc. Prepared granules was compressed (9mm FFBE Punch) using Cadmach Machine.

\section{Precompression Studies:}

\section{Angle of Repose ( $\theta):^{9}$}

The frictional forces in a loose powder can be measured by the angle of repose. It is an indicative of the flow 
properties of the powder. It is defined as maximum angle possible between the surface of the pile of powder and the horizontal plane.

$$
\theta=\tan -1(h / r)
$$

Where, $\theta$ is the angle of repose, $\mathrm{h}$ is the height in $\mathrm{cm}, \mathrm{r}$ is the radius in $\mathrm{cm}$.

\section{Method:}

The powder mixture was allowed to flow through the funnel fixed to a stand at definite height (h). The angle of repose was then calculated by measuring the height and radius of the heap of powder formed. Care was taken to see that the powder particles slip and roll over each other through the sides of the funnel.

\section{Bulk density: ${ }^{10}$}

Bulk density is the ratio between a mass of granules and its bulk volume. It is expressed by gm/cc.

\section{Method:}

A bulk density $(\mathrm{g} / \mathrm{ml})$ is determined by pouring presieved (40 \# mesh) bulk drug in to a graduated cylinder via a large funnel and measuring the volume and weight.

$$
\text { Bulk Density }=\frac{\text { Mass of powder }(M)}{\text { Bulk volume of the powder }(V)}
$$

Tapped Density
Tapped density is the ratio between mass of granules and volume of the granules after tapping; it is expressed by $\mathrm{gm} / \mathrm{cc}$.

\section{Method:}

Tapped density is determined by placing a graduated cylinder containing a known mass of drug or formulation on a mechanical tapper apparatus, which is operated for a fixed number of taps (500) until the powder bed volume has reached a minimum.

$$
\text { Tapped Density }=\frac{\text { Weight of powder }}{\text { Tapped volume of the powder }}
$$

\section{Carr's index: ${ }^{11}$}

This was measured for the property of a powder to be compressed; as such they are measured for relative importance of interparticulate interactions. Carr's index was calculated by following equation-

$$
\text { Carr's index }=\frac{\text { Tapped density }- \text { Bulk density }}{\text { Tapped density }} \times 100
$$

\section{Hausner ratio:}

Hausner ratio was calculated by following equation

$$
\text { Hausner"s ratio }=\frac{\text { Tapped density }(\rho \text { Bmax })}{\text { Bulk density }(\rho \text { Bmin })}
$$

Where, $(\rho \mathrm{Bmax})=$ tapped density, $(\rho \mathrm{Bmin})=$ bulk density.

Table 1: Composition of sustained release matrix tablets of Salbutamol sulphate (Weight in mg)

\begin{tabular}{|c|l|c|c|c|c|c|c|c|c|c|}
\hline Sr. No & \multicolumn{1}{|c|}{ Ingredients (mg) } & F1 & F2 & F3 & F4 & F5 & F6 & F7 & F8 & F9 \\
\hline 1. & Salbutamol sulphate & 8 & 8 & 8 & 8 & 8 & 8 & 8 & 8 & 8 \\
\hline 2. & HPMC K100M & 40 & 50 & 60 & -- & -- & -- & -- & -- & -- \\
\hline 3. & HPMC K15M & -- & -- & -- & 40 & 50 & 60 & -- & -- & -- \\
\hline 4. & Ethyl Cellulose & -- & -- & -- & -- & -- & -- & 40 & 50 & 60 \\
\hline 5. & Lactose Monohydrate & 196 & 186 & 176 & 196 & 186 & 176 & 196 & 186 & 176 \\
\hline 6. & Isopropyl alcohol & q.s. & q.s. & q.s. & q.s. & q.s. & q.s. & q.s. & q.s. & q.s. \\
\hline 7. & Magnesium stearate & 4 & 4 & 4 & 4 & 4 & 4 & 4 & 4 & 4 \\
\hline 8. & Talc & 2 & 2 & 2 & 2 & 2 & 2 & 2 & 2 & 2 \\
\hline 9. & Total weight (mg) & 250 & 250 & 250 & 250 & 250 & 250 & 250 & 250 & 250 \\
\hline
\end{tabular}

\section{Postcompression Studies:}

\section{Tablet description: ${ }^{10}$}

The general appearance of a tablet, its visual identity and overall "elegance", is essential for consumer acceptance.

\section{Thickness and diameter:}

The thickness of individual tablets was measured with a micrometer, which permits accurate measurement and provides information on the variation between tablets. The tablet thickness should be controlled within a $\pm 5 \%$ variation of a standard value.

\section{Hardness:}

Tablet required certain amount of strength, or hardness and resistance to friability, withstand mechanical shock of handling in manufacture, packaging, and shipping. Tablet hardness is also called as crushing strength. Monsanto hardness tester was used to check the hardness of the tablets.

\section{Friability:}

The friability of the tablets was measured in a Roche friabilator (Camp-bell Electronics,

Mumbai, India). Tablets of a known weight $\left(\mathrm{W}_{0}\right)$ or a sample of tablets are dedusted in a drum for a fixed time (100 revolutions) and weighed (W) again. Percentage friability was calculated from the loss in weight as given in 
equation as below. The weight loss should not be more than $1 \%$ w/w. ${ }^{12}$

$$
\% \text { Friability }=\left(\mathrm{W}_{0}-\mathrm{W}\right) / \mathrm{W}_{0} \times 100
$$

\section{Weight Variation Test}

To study weight variation, 20 tablets of each formulation were weighed using an electronic balance (Electro lab, India), and the test was performed according to the official method. $^{13}$

\section{Determination of drug contents:}

The tablets were powdered, and $8 \mathrm{mg}$ equivalent weight of Salbutamol sulphate in tablet powder was accurately weighted and transferred into a $100 \mathrm{~mL}$ volumetric flask. Initially, $10 \mathrm{~mL}$ of phosphate buffer (pH6.8) was added and shaken for $10 \mathrm{~min}$. then, the volume was made up to $100 \mathrm{~mL}$ with buffer. Subsequently, the solution in volumetric flask was filtered, and $1 \mathrm{~mL}$ of the filtrate was diluted and analyzed at $276 \mathrm{~nm}$ using UV-visible spectrophotometer (Labindia).

\section{In vitro dissolution:}

The in vitro dissolution study was carried out using eight station dissolution rate test apparatus USP type-II (Basket type) at 50rpm. The dissolution medium consisted of $900 \mathrm{~mL} 0.1 \mathrm{~N} \mathrm{HCl}(\mathrm{pH} \mathrm{1.2)}$ for first $2 \mathrm{hrs}$ followed by phosphate buffer ( $\mathrm{pH}$ 6.8) from 2 to $12 \mathrm{hrs}$. Temperature of the medium should maintain at $37^{0} \pm 0.5^{0} \mathrm{C}$.

\section{RESULTS AND DISCUSSION:}

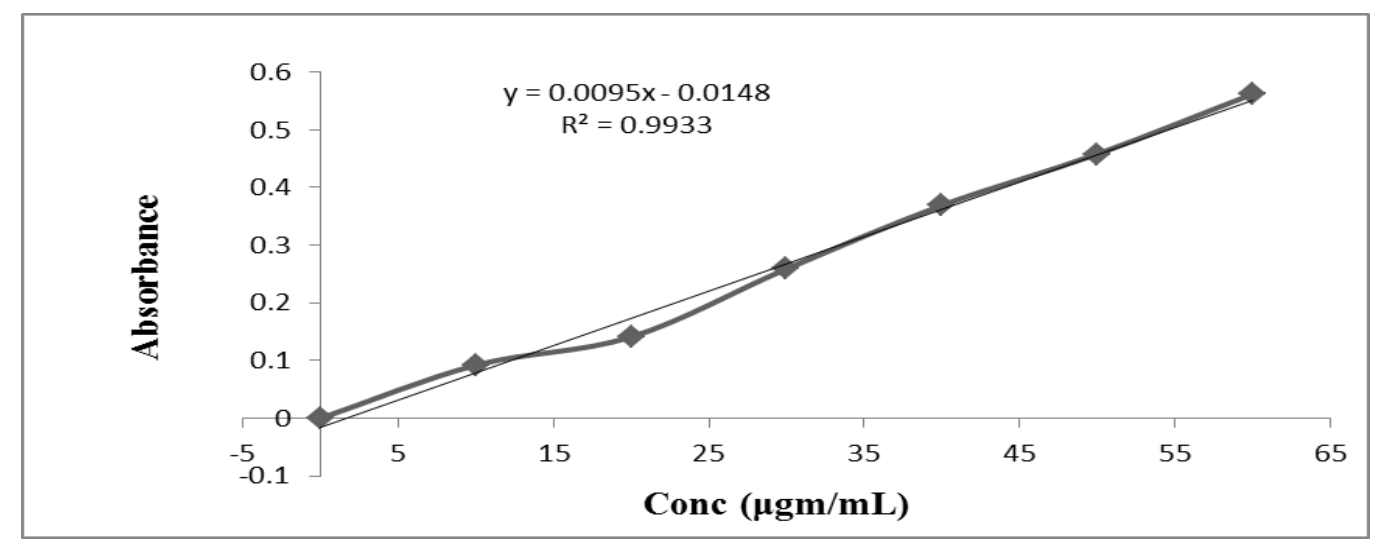

Figure 1: Standard calibration curve of Salbutamol sulphate in $0.1 \mathrm{~N} \mathrm{HCl}$ (pH 1.2)

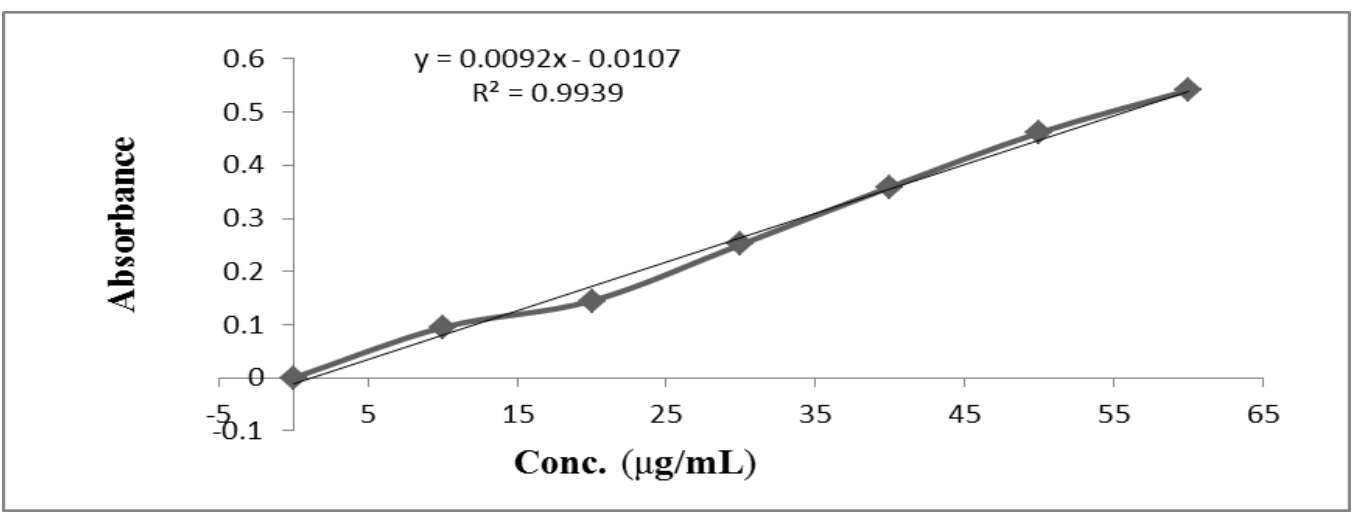

Figure 2: Standard calibration curve of Salbutamol sulphate in Phosphate Buffer (pH 6.8)

\section{Evaluation Studies}

Table 2: Evaluation of Granules

\begin{tabular}{|c|c|c|c|c|c|}
\hline F & $\begin{array}{c}\text { Mean Angle of } \\
\text { repose* } \pm \text { S.D. }\end{array}$ & $\begin{array}{c}\text { Bulk density } * \\
(\mathrm{~g} / \mathrm{cc}) \pm \text { S.D }\end{array}$ & $\begin{array}{c}\text { Tapped density* } \\
(\mathrm{g} / \mathrm{cc}) \pm \text { S.D. }\end{array}$ & $\begin{array}{c}\text { Compressibility } \\
\text { Index* }(\%) \pm \text { S.D. }\end{array}$ & $\begin{array}{c}\text { Hausner's Ratio* } \pm \\
\text { S.D. }\end{array}$ \\
\hline F1 & $27^{\circ} 28^{\prime} \pm 1.469$ & $0.346 \pm 0.0072$ & $0.383 \pm 0.0023$ & $14.78 \pm 1.547$ & $1.138 \pm 0.0197$ \\
\hline F2 & $31^{\circ} 65^{\prime} \pm 1.118$ & $0.341 \pm 0.0043$ & $0.384 \pm 0.0024$ & $13.15 \pm 1.598$ & $1.126 \pm 0.0075$ \\
\hline F3 & $33^{\circ} 26^{\prime} \pm 1.034$ & $0.311 \pm 0.0025$ & $0.364 \pm 0.0027$ & $9.45 \pm 0.075$ & $1.103 \pm 0.0009$ \\
\hline F4 & $30^{\circ} 19^{\prime} \pm 1.205$ & $0.334 \pm 0.0034$ & $0.378 \pm 0.0028$ & $14.62 \pm 0.292$ & $1.118 \pm 0.0036$ \\
\hline F5 & $24^{\circ} 05^{\prime} \pm 1.259$ & $0.335 \pm 0.0018$ & $0.377 \pm 0.0031$ & $12.01 \pm 0.262$ & $1.113 \pm 0.0032$ \\
\hline F6 & $38^{\circ} 65^{\prime} \pm 2.506$ & $0.347 \pm 0.0022$ & $0.380 \pm 0.0023$ & $12.9 \pm 0.075$ & $1.108 \pm 0.0009$ \\
\hline F7 & $31^{\circ} 17^{\prime} \pm 1.950$ & $0.305 \pm 0.0028$ & $0.392 \pm 0.0025$ & $11.48 \pm 0.192$ & $1.139 \pm 0.0025$ \\
\hline F8 & $35^{\circ} 26^{\prime} \pm 0.922$ & $0.314 \pm 0.0019$ & $0.391 \pm 0.0082$ & $12.41 \pm 1.392$ & $1.145 \pm 0.0182$ \\
\hline F9 & $30^{\circ} 45^{\prime} \pm 1.118$ & $0.373 \pm 0.0077$ & $0.406 \pm 0.0034$ & $11.84 \pm 0.217$ & $1.130 \pm 0.0027$ \\
\hline
\end{tabular}


Table 3: Evaluation of Tablets

\begin{tabular}{|c|c|c|c|c|c|}
\hline $\mathrm{F}$ & Thickness $(\mathrm{mm})^{\#}$ & Hardness $\left(\mathrm{kg} / \mathrm{cm}^{2}\right)^{\#}$ & Friability $\quad(\%)^{*}$ & $\begin{array}{l}\text { Average Weight } \\
\text { Variation }(\mathrm{mg})^{\#}\end{array}$ & $\begin{array}{c}\text { Drug Content } \\
\text { Uniformity }(\%)^{*}\end{array}$ \\
\hline F1 & $5.62 \pm 0.238$ & $7.9 \pm 0.418$ & 0.14 & $250 \pm 1.52$ & $99.11 \pm 2.01$ \\
\hline F2 & $5.64 \pm 0.240$ & $7.2 \pm 1.036$ & 0.04 & $249 \pm 1.77$ & $101.87 \pm 3.04$ \\
\hline F3 & $5.70 \pm 0.223$ & $7.6 \pm 0.651$ & 0.012 & $252 \pm 1.55$ & $99.39 \pm 1.31$ \\
\hline F4 & $5.72 \pm 0.238$ & $7.5 \pm 0.790$ & 0.05 & $250 \pm 1.47$ & $98.69 \pm 1.32$ \\
\hline F5 & $5.96 \pm 0.230$ & $7.7 \pm 0.570$ & 0.17 & $251 \pm 1.75$ & $99.34 \pm 2.01$ \\
\hline F6 & $5.52 \pm 0.238$ & $7.5 \pm 0.790$ & 0.11 & $250 \pm 1.52$ & $99.87 \pm 2.01$ \\
\hline F7 & $5.90 \pm 0.212$ & $7.9 \pm 0.651$ & 0.06 & $249 \pm 1.33$ & $100.75 \pm 2.73$ \\
\hline F8 & $5.90 \pm 0.212$ & $7.7 \pm 0.570$ & 0.17 & $251 \pm 1.54$ & $100.43 \pm 2.01$ \\
\hline F9 & $5.90 \pm 0.045$ & $7.8 \pm 0.836$ & 0.08 & $252 \pm 1.44$ & $99.31 \pm 2.35$ \\
\hline
\end{tabular}

In Vitro Dissolution Study

In-Vitro Dissolution Profile of Formulations F1-F9 \% Cumulative drug release (\% CDR)

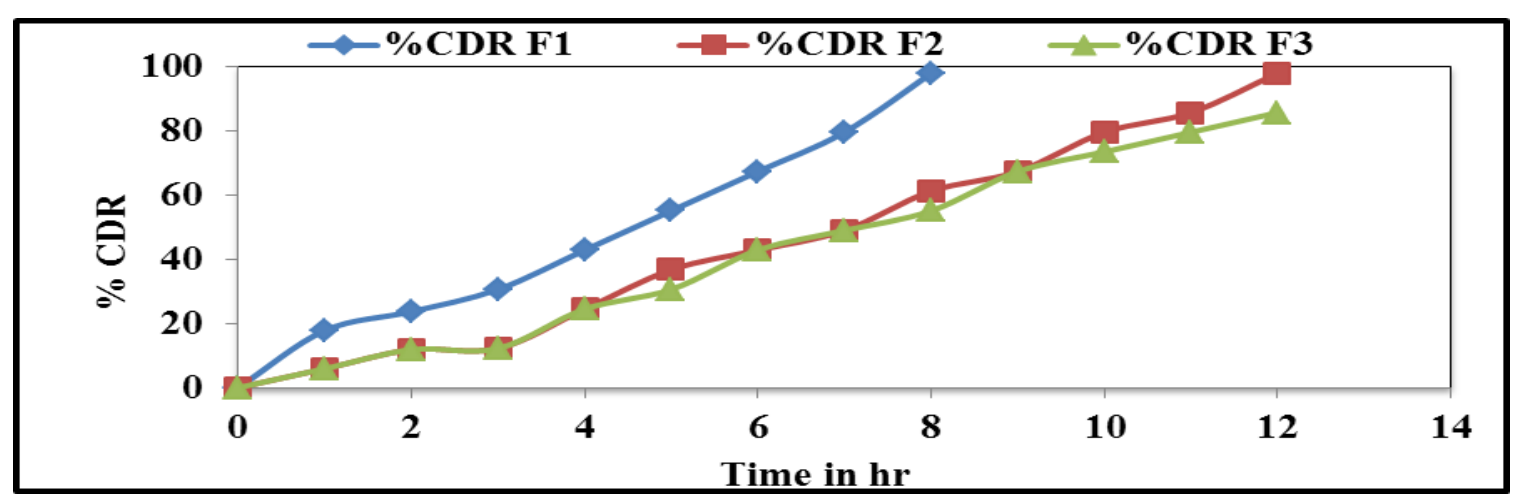

Figure 3: In-Vitro Dissolution Profile of Formulations F1-F3

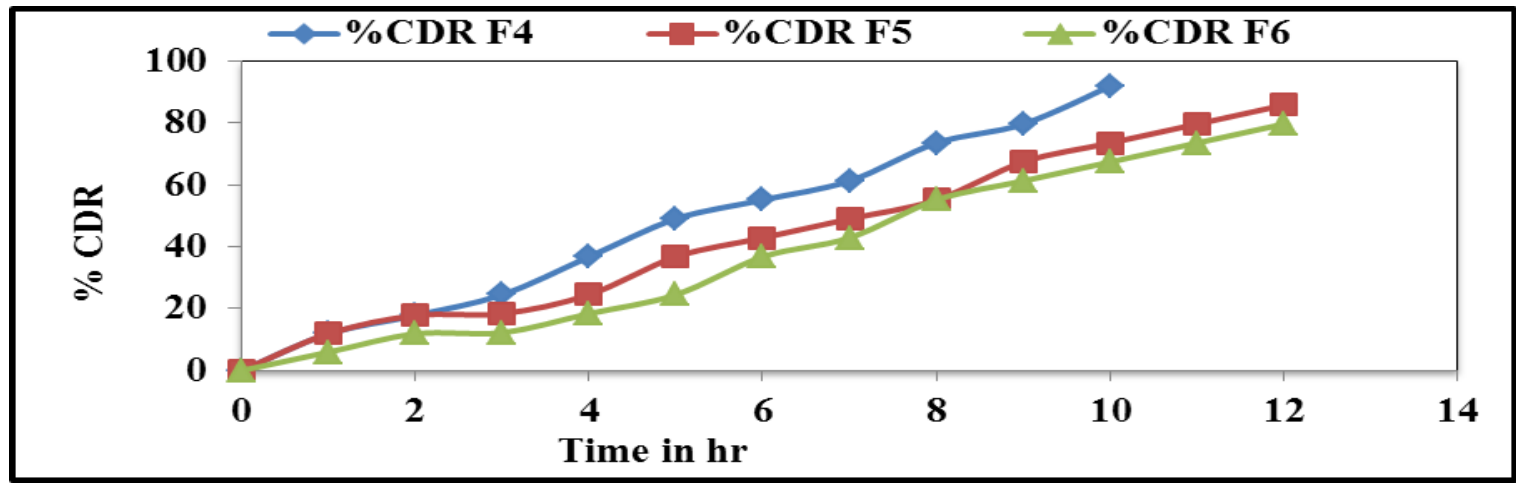

Figure 4: In-Vitro Dissolution Profile of Formulations F4-F6

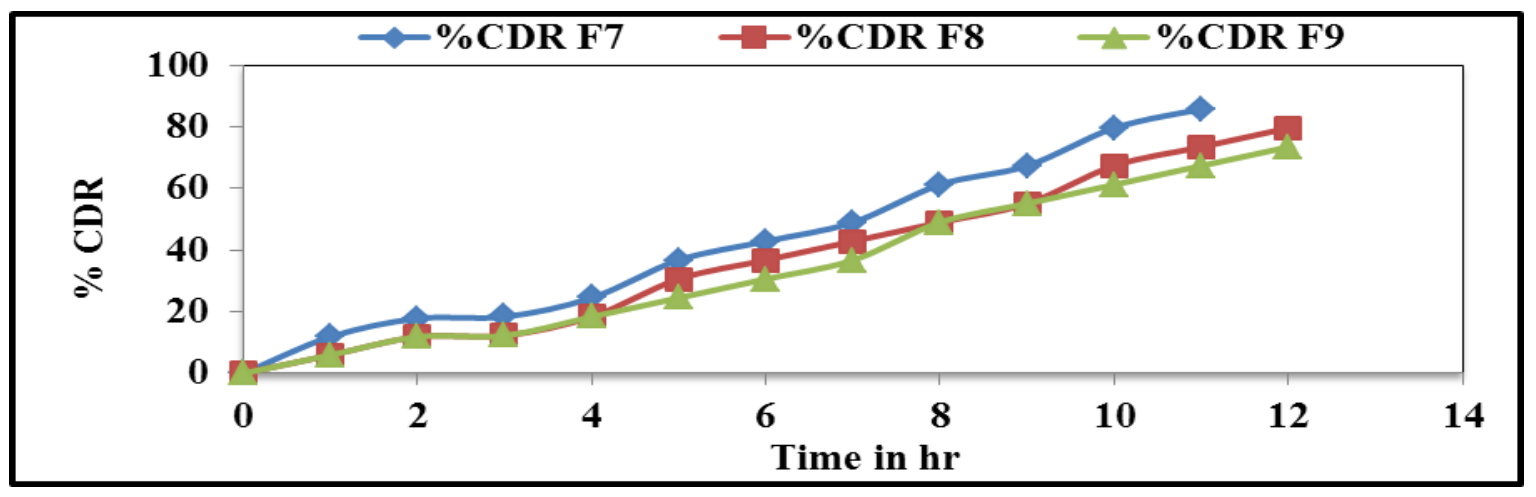

Figure 5: In-Vitro Dissolution Profile of Formulations F7-F9 
KINETIC MODELING:

Table 4: Drug release kinetics of formulations F1-F9

\begin{tabular}{|c|c|c|c|c|c|}
\hline \multirow{2}{*}{ Formulation Code } & Zero order & First order & Higuchi's & \multicolumn{2}{|c|}{ Peppa's } \\
\cline { 2 - 5 } & $\mathbf{R}^{\mathbf{2}}$ & $\mathbf{R}^{\mathbf{2}}$ & $\mathbf{R}^{\mathbf{2}}$ & Slope & $\mathbf{R}^{\mathbf{2}}$ \\
\hline F1 & 0.9863 & 0.6927 & 0.8846 & 1.4693 & 0.7047 \\
\hline F2 & 0.9889 & 0.7304 & 0.8715 & 1.4614 & 0.908 \\
\hline F3 & 0.9908 & 0.9292 & 0.8852 & 1.4250 & 0.9031 \\
\hline F4 & 0.9956 & 0.8785 & 0.9156 & 1.3913 & 0.7911 \\
\hline F5 & 0.9915 & 0.9258 & 0.9051 & 1.2472 & 0.7966 \\
\hline F6 & 0.9839 & 0.9369 & 0.8667 & 1.3871 & 0.8998 \\
\hline F7 & 0.9859 & 0.8934 & 0.8810 & 1.2885 & 0.7905 \\
\hline F8 & 0.9884 & 0.9241 & 0.8747 & 1.3739 & 0.8974 \\
\hline F9 & 0.9855 & 0.939 & 0.8674 & 1.3344 & 0.8925 \\
\hline
\end{tabular}

The drug release kinetics of formulations F1-F9 was obeyed on zero order release kinetics, as the plots showed a highest linearity $\left(\boldsymbol{r}^{2}=\mathbf{0 . 9 9 5 6}\right)$. It can be said that the drug release obeying the zero order release rate kinetics is concentration dependent.

\section{SUMMARY AND CONCLUSION:}

The study was undertaken with an aim to formulation and evaluation of sustained release matrix tablets using various polymers like HPMC K100M, HPMC K15M and Ethyl cellulose. Lactose monohydrate used as diluents, magnesium sterate used as lubricant and talc was used as glidant. The formulations were subjected to prefomulation studies, where they were examined for physical mixture compatibilities using FTIR, where drug peaks appeared intact, indicating that the drug is stable. The $\lambda_{\max }$ of the Salbutamol sulphate were found at $276 \mathrm{~nm}$ in two media viz., $0.1 \mathrm{~N} \mathrm{HCl}(\mathrm{pH} \mathrm{1.2)}$ and phosphate buffer ( $\mathrm{pH}$ 6.8). Calibration curves of the pure drug were found using $0.1 \mathrm{~N} \mathrm{HCl}(\mathrm{pH} \mathrm{1.2)}$ ) and phosphate buffer (pH 6.8) by UV Spectrophotometer. The regression values were 0.9933 in $0.1 \mathrm{~N} \mathrm{HCl}(\mathrm{pH} \mathrm{1.2)}$ ) and 0.9939 in phosphate buffer $(\mathrm{pH}$ 6.8). The prepared granules were evaluated for pre-compression parameters, the results are found to be in the acceptable limits. Tablets were prepared by wet granulation method by using $9 \mathrm{~mm}$ round flat face beveled edges punch on 10 station single punch rotary tablet compression machine. Tablets were evaluated for post-compression parameters, In vitro drug release as per official procedures. Based on the above study it was concluded that: Sustained release matrix tablets of Salbutamol sulphate were prepared using HPMC K100M, HPMC K15M and Ethyl cellulose as the release retardant polymer. The results of various evaluation parameters of pre-compression and post-compression studies of the formulations were found to be satisfactory. Among all the formulations prepared and evaluated, formulation F2 containing HPMC K100M showed better release pattern in comparison with other formulations. By using different concentrations of polymers it was also possible to retard the release of Salbutamol sulphate upto $12 \mathrm{hrs}$. Various kinetic treatments of the drug release data for formulations F1 to F9 showed that $\mathrm{R}^{2}$ value was highest for zero order release model indicating zero order drug release mechanism. Based on the results of the research work and the objectives envisaged in the research work, formulation of sustained release matrix tablets of Salbutamol sulphate using various polymers (i.e. HPMC K100M, HPMC K15M and ethyl cellulose) has been achieved successfully.

\section{REFERENCES:}

1. Goodman and Gilman's the pharmacological basis of therapeutics, 10th edition, 2001: 991-992 1758-1760.

2. Brahmankar DM, Jaiswal SB. "Biopharmaceutics and pharmacokinetics a treatise" 1st ed. Vallabh prakashan; New Delhi: 1995: 64-70.

3. Sallsa T. Veiga F, Pina ME. Oral controlled - release dosage forms Cellulose ether polymers in hydrophilic - matrices. Drug Dev Ind Pharm 1997; 23: 929 - 938.

4. Alderman DA. A review of cellulose ethers in hydrophilic matrices for oral controlled - release dosage forms. Int S Pharm Tech Prod Manuf 1984; 5:1-9.

5. Singh A, Mohamed R. Design and Evaluation of controlled release tablet of Lipid lowering agents for hyperlipidemia. Int $\mathbf{J}$ Pharm Pharma Sci 2011;3(4):201-08.

6. Lachman Leon, Lieberman Herbert A. Pharmaceutical Dosage Forms: Tablets. In: The Theory and Practice of Industrial Pharmacy. Lea and Febiger, U.S.A, 1991; 3rd edition: 293-345.

7. Subrahmanyam CVS.Textbook of physical pharmaceutics. 2nd ed. Delhi : Vallaba prakashan;2003.p.180-234.

8. Modern pharmaceutics, revised and expanded, edited by Gilbert S. banker, Christopher T. Rhodes. 2002.

9. Chein YW. Oral Drug delivery and delivery systems. In: Novel drug delivery systems. Marcel Dekker, Inc., New York, 2002; 50; 3rd edition: 139-96.

10. Gohel MC, Patel TP, BarigyaSH. Studies in preparation and evaluation of $\mathrm{pH}$ independent sustained - release matrix tablets of Verapamil Hcl using directly compressible Eudragits. Pharam Dev Technol, 2003; 8: 323 - 333. Pubmed Dol: 10. 1081 / PDT 120024686.

11. Anroop B. Nair, Hiral vyas, Ashok Kumar. Controlled release matrix uncoated tablets of enalapril maleate using HPMC alone, J Basic Clinical Pharm 2010; 1(2).

12. Shantveer V. Salger, Lingaraj S. Danki, Abdul Sayeed, Shivanand Hiremath.Formulation and in-vitro evaluation of sustained release matrixtablets of anti-hypertensive drug propranolol hydrochloride, Scholars Research Library. Der Pharmacia Lettre, 2010;2(5):12-22.

13. Yadav Amit.S, Ashok Kumar P, Vinod R, Someshwara Rao B, Suresh V Kulkarni. Design and Evaluation of Guar Gum Based Controlled Release Matrix Tablets of Zidovudine. J Pharma Sci Technol 2010; 2(3):156-162. 